\title{
A digital tool for incorporating right atrial pressure into Fractional flow reserve determination
}

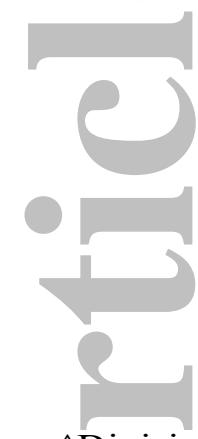

\author{
Sabir Meah $^{\#}$ and Hitinder S Gurm^^, MD, FASCI
}

${ }^{\#}$ Skyline High School, Ann Arbor and

${ }^{\wedge}$ Division of Cardiovascular Medicine, Department of Medicine, University of Michigan,

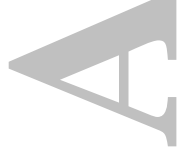

Ann Arbor, Michigan

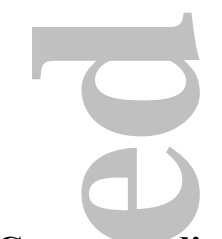

\section{Corresponding Author:}

Hitinder S. Gurm, MD

2A 394, 1500 East Medical Ctr Drive,

University of Michigan Cardiovascular Center

Ann Arbor, MI 48109-5853

hgurm@med.umich.edu

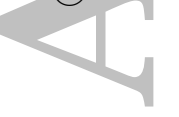

Word Count: 682

This is the author manuscript accepted for publication and has undergone full peer review but has not been through the copyediting, typesetting, pagination and proofreading process, which may lead to differences between this version and the Version record. Please cite this article as doi:10.1002/ ccd.26820. 
Dear Editor,

Fractional Flow Reserve (FFR) determination is commonly performed in cardiac catheterization laboratories to assess the hemodynamic significance of coronary artery stenosis. FFR is a ratio of the current maximum achievable flow rate to the maximum achievable rate in the absence of a coronary artery stenosis, making it an assessment of the functionality of a coronary artery in the presence of a stenosis ${ }^{1}$. In practice the myocardial fractional flow reserve (FFR) is the maximum myocardial flow achievable in the presence of an epicardial stenosis in relation to the theoretical maximum flow without the obstruction and is calculated by simultaneous measurement of mean aortic $(\mathrm{Pa})$, right atrial (Pra), and distal coronary pressure $(\mathrm{Pd})$ under conditions of maximal hyperemia $[\mathrm{FFR}=(\mathrm{Pd}-\mathrm{Pra}) /(\mathrm{Pa}-\mathrm{Pra})]$. Right atrial pressure is typically ignored in traditional FFR calculations because its impact is assumed to be negligible, but ignoring it can significantly misclassify the hemodynamic significance of a lesion, especially in patients with high right atrial pressures and low systemic pressures.

While it is probably unrealistic and unnecessary to correct the FFR for right atrial pressure in every patient, it may be of clinical significance in specific scenarios such as patients with pulmonary hypertension and right heart failure as well as those on hemodialysis ${ }^{2-4}$.

In practice, clinicians rely on automatically calculated FFR values provided by the commercially available systems that do not allow for the incorporation of the right atrial pressure in the calculation. We have developed a simple free mobile application, available on the Apple App Store (https://itunes.apple.com/us/app/corrected-ffr/id1084880562?mt=8) and Android Google Play Store (https://play.google.com/store/apps/details?id=appinventor.ai_snislam64.CorrectedFFR2), that 
allows the user to input the machine calculated FFR at peak hyperemia, the mean aortic pressure at peak hyperemia and the right atrial pressure (ideally also at obtained at the time of peak hyperemia) and have found this to result in clinically impactful change in FFR in a subset of scenarios usually characterized by high right heart filling pressures.

A recent study has questioned the need for incorporating right atrial pressure assessment into routine clinical assessment of FFR but it is important to recognize that the majority of patients in that study had low right atrial pressures and the impact of routine ascertainment of right atrial pressure becomes important only when right atrial pressure is high and the FFR is in the borderline range ${ }^{5}$. Thus in a patient with a relatively "high" FFR but typical symptoms, a corrected FFR might yield a value that would be considered pathological but conversely a low FFR will not become clinically 'non-significant' after incorporation of the RA pressure. A selective approach incorporating RA pressure derived correction of the FFR in the setting of borderline FFR values in the appropriate clinical settings might help guide appropriate clinical care.

\section{Disclosures and Funding:}

Hitinder S. Gurm receives research funding from Blue Cross Blue Shield of Michigan, the National Institutes of Health and is a consultant for Osprey Medical. The App described in this report was developed by Sabir Meah during a summer research elective. No specific funding was used for this project. None of the authors have any conflicts directly relevant to this study. 


\section{References:}

1. Pijls NHJ, de Bruyne B, Peels K, et al. Measurement of Fractional Flow Reserve to Assess the Functional Severity of Coronary-Artery Stenoses. New England Journal of Medicine 1996;334:1703-8.

2. Layland J, Wilson AM, Whitbourn RJ, et al. Impact of right atrial pressure on decision-making using fractional flow reserve (FFR) in elective percutaneous intervention. International journal of cardiology 2013;167:951-3.

3. Takashima H, Kurita A, Toda Y, et al. Impact of right atrial pressure as venous pressure on fractional flow reserve calculation in patients with hemodialysis. European heart journal 2013;34.

4. Kurita A, Takashima H, Waseda K, et al. Impact Of Venous Pressure on Fractional Flow Reserve Measurement in Intermediate Coronary Lesions of Hemodialysis Patients. Journal of the American College of Cardiology 2013;61.

5. Toth GG, De Bruyne B, Rusinaru D, et al. Impact of Right Atrial Pressure on Fractional Flow Reserve Measurements: Comparison of Fractional Flow Reserve and Myocardial Fractional Flow Reserve in 1,600 Coronary Stenoses. JACC Cardiovascular interventions 2016;9:453-9. 